\title{
Quality evaluation of apple fruit: A Survey
}

\author{
Komal Sindhi \\ M.E. Student \\ Department of Information \\ Technology \\ GCET, V. V. Nagar, Affiliated to \\ G.T.U. \\ Gujarat, India
}

\author{
Jaymit Pandya \\ Assistant Professor \\ Department of Information \\ Technology \\ GCET, V.V. Nagar, Affiliated to \\ G.T.U. \\ Gujarat, India
}

\author{
Sudhir Vegad \\ Associate Professor \\ Department of Information \\ Technology \\ ADIT, Karamsad, Affiliated to \\ G.T.U. \\ Gujarat, India
}

\begin{abstract}
Disease recognition has been huge research area nowadays because inspection of quality of fruits at an early stage prevents spreading of disease to the other areas of fruit as well as helps to reduce great economic losses in agricultural sectors and industries. Different types of diseases exist in different fruits. The focus of the present research work is on quality evaluation of apple fruit. The basic process for defect detection in fruits is basically divided into two major steps; feature extraction and classification .Feature extraction involves extracting features like color, texture and shape from fruit image. The output of this are feature vectors which are given as an input to the classifier. Finally, the classifier categorizes them into appropriate classes. The accuracy of this process depends on many factors like number of input images, method chosen for pre processing, features extracted, classifier chosen, etc.
\end{abstract}

\section{Keywords}

Digital image processing, Quality Evaluation, apple disease, feature extraction, classification

\section{INTRODUCTION}

India ranks second in the world in the production of fruit [1] and ranks fifth in the world in exporting apples [2]. The quality of fruits plays a crucial role since they are been used in variety of applications like export, producing fruit juice, etc. Detecting defects in fruits at an early stage can help reduce additional infection spreading to other parts of the fruit as well as economic losses in agricultural industries. Thus quality evaluation of fruits has proved to be a major research area in computer vision to get closer to human levels of recognition. A manual recognition method called scouting described in [20] has been mainly used. It is basically a stress monitoring method for fruits which is performed by experts; but it is a labor intensive and time consuming method. Polymerase chain reaction which is a molecular technique used for the identification of fruit diseases but it requires detailed sampling and processing [3]. Hence computer vision turned out to be a better option for health inspection of fruits. In this paper, main focus has been laid on quality evaluation of apple fruit. It also shows main diseases occurring in apple fruit, basic steps for the quality detection and finally the comparison of techniques used for the same.

From image processing point of view, apple varieties can be grouped into two: those having mono-colored skin (e.g. Golden Delicious, Granny Smith) and those having bi-colored skin (e.g. Jonagold, Fuji). Inspection of the latter group by image processing is more problematic because of color transition areas [13]. According to a plant pathology factsheet, common diseases found in apple are: Apple Scab, Apple Rot, Apple Blotch and Cork Spots.
Apple Scab: It is the most economically destructive disease of apple in the world [5]. Apple scabs are grey or brown corky spots.

Apple Rot: Usually, bitter rot infections produce slightly sunken, circular brow spots that may be surrounded by a red halo. When the spot becomes nearly an inch in diameter, spore-bearing structures appear in concentric circles on the diseased apple surface [4]

Apple Blotch: These are dark, shiny raised blotches with irregular or lobed edges appear on the surface of fruit having this fungal disease [4].

Cork Spots: This problem is not caused by fungi, but by calcium deficiency. The symptoms, small, circular, reddish or dark sunken spots with brown flesh beneath, are similar to some fungal diseases [4]. The above described diseases are shown in fig 1.

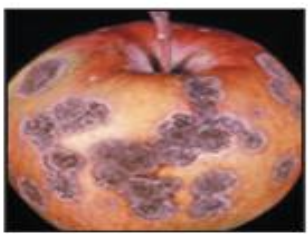

(a) Apple scab

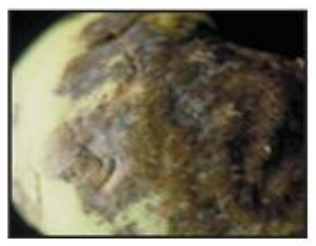

(c) Apple Blotch

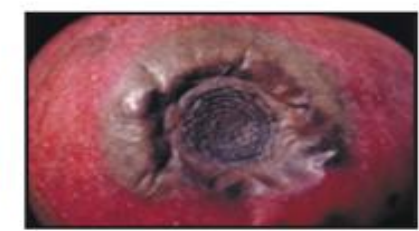

(b) Apple Rot

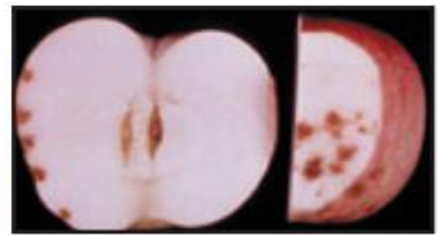

(d) Cork spots
Figure 1 Common Apple Diseases [4]

\section{BASIC PROCESS FOR FRUIT QUALITY EVALUATION}

As shown in the fig 2, there are mainly two parts in the process:
(i) Feature extraction

(ii) Classification 


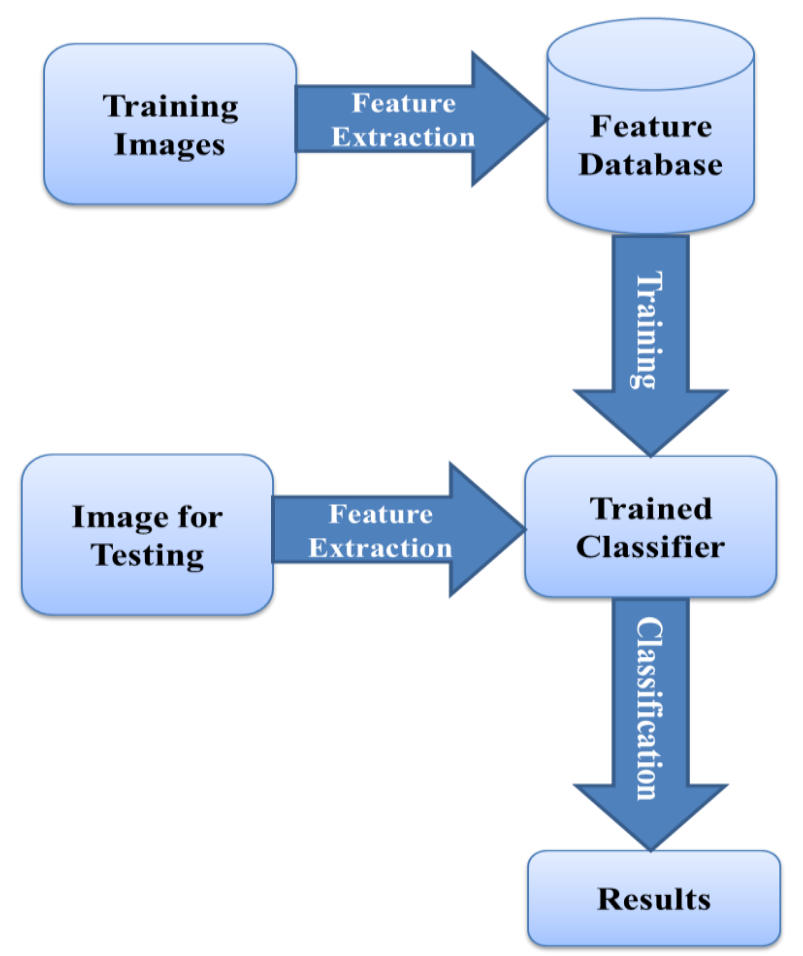

Figure 2 Basic process for fruit quality evaluation

Pre processing: In order to extract any specific information, image pre processing steps are carried out before the actual analysis [23]. Pre processing refers to the initial processing of input image to eliminate the noise and correct the distorted or degraded data. This includes techniques like grayscale conversion, binarization, smoothing, filtering, edge detection, etc. used for the enhancement of the image.

Feature extraction: It is a key step in most pattern analysis tasks [21]. In case of fruits; it is done by extracting different features of color, texture, shape ,intensity, etc that can differentiate defected fruits from the normal ones.

Color is one of the most important features of images. Color features are defined subject to a particular color space or model. A number of color spaces have been used in literature, such as RGB, LUV, HSV and HMMD. Once the color space is specified, color feature can be extracted from images or regions. A number of important color features have been proposed in the literatures, including color histogram [13], color moments $(\mathrm{CM})$, color coherence vector $(\mathrm{CCV})$ and color correlogram, etc [22]. Texture is one of the important features of an image. Not only fruits, it plays an important role in recognizing visual attribute that can easily differentiate images. Previously several texture feature extraction procedure have been developed like GLCM (Grey Level Cooccurrence Matrix) approach, SFTA algorithm or DWT (Discrete wavelet transform) method for image classification [24]. Shape is one of the primary visual features in CBIR. Shape descriptors fall into two categories i.e., contour-based and region-based . Contour-based shape descriptors use only the boundary information by ignoring the shape interior content while region-based shape descriptors exploit interior pixels of shape . Region-based shape descriptors can be applied to more general shapes. However, contour-based shape descriptors have limitations of extracting complex shapes. Hence, region based shape descriptors viz., Moment Invariants (MI), Zernike Moments (ZM) and Legendre
Moments (LM) are preferred to represent the shape content of an image [25].

Training database: These features are stored in a database which is used to train the classifier.

Classification:The input to the classifier are the features extracted from the training images .As a result of this, the classifier learns about the various characteristics of different categories of the fruit. Finally, when the test images are given, it is able to classify them into particular category of disease in the fruit as the result. Some of the classifiers used are Naïve Bayes, PCA (Principal Component Analysis), Support Vector Machine, Neural Networks, etc.

\section{TECHNIQUES USED}

Since 1980's, a lot of work has been done for the quality evaluation of apples. Most of it is included in the presented paper and is described below.

A method based on colour information was proposed in [6] to detect defects on 'Golden Delicious' apples. To segment the defects, each pixel of an apple image was compared with the model. If it matched the pixel, it was considered as belonging to healthy tissue, otherwise as a defect. Two other steps refined the segmentation, using either parameters computed on the whole fruit, or values computed locally.

From the defect segmentation of jonagold apples [7], color, shape and texture descriptors were used for feature extraction and these features were given as an input to Linear Discriminant classifier which gave an accuracy of $73 \%$. In 2005, artificial neural network based segmentation was done on apples in [8], from which different features were extracted and various classifiers were used to grade them. Linear Discriminant, Nearest neighbour, fuzzy nearest neighbour, Adaboost and Support Vector Machines classifiers were used, among which last two showed the highest accuracy.

A Gabor feature-based apple quality inspection was done by using kernel PCA for classification. First, Gabor wavelet decomposition of whole apple NIR images was employed to extract appropriate Gabor features. Then, the kernel PCA method with polynomial kernels was applied in the Gabor feature space to handle non-linear separable features. The results showed the effectiveness of the Gabor-based kernel PCA method in terms of its absolute performance and comparative performance compared to the PCA, kernel PCA with polynomial kernels, Gabor-based PCA and the support vector machine methods.[9]

K. Vijayrekha proposed a multivariate image analysis technique for defect segmentation of apples [10], which was based on multi way PCA for decomposition. Jin-jing Wang used an apple harvesting robot for apple recognition. At first, vector median filter is used. Secondly, segmentation of the images based on region growing method and color properties is done. Then, color properties and shape properties of color image are extracted, and classification method of SVM for recognition of apple fruit is used [11]. A digital parameterization method was proposed to measure size, shape and surface spottiness. [12]. An automated system for grading jonagold apples was brought into existence in which statistical, textural and geometric features were extracted after segmentation. Using these features, statistical and syntactical classifiers are trained for two- and multi-category grading of the fruits [13]. A segmentation method for apple classification was proposed based on fuzzy clustering algorithms. Here pre processing is done by using active contour model which causes increase in segmentation accuracy. 
An analysis was carried out on images of 187 apple fruits, shows that classification done based on median of PDF. In order to avoid the mismatch in grading the same it has been classify further using Histogram Intersection, which determines the closeness between two images [15]

A novel system was presented in [16] that included dividing images into planes called windows. Basic steps were pre processing, dividing the image into windows, features collection, window elimination and classification or decision making step . Detection of apple fruit done in [17] was based on color and texture features and the results were compared in both RGB and HSV color spaces. Results showed that CLBP (Complete Local Binary Patterns) showed the highest accuracy. Later on in the work done on apple and grapes in [18], two main apple diseases focused were apple scab and apple rot. Back propagation concept was used for the weights training of the database. The images were classified and mapped to their respective categories on basis of three feature vectors, namely, color, texture and morphology. From these morphology gave $90 \%$ result which is the highest. A method was introduced in [19] that used global threshold segmentation in $\mathrm{L}^{*} \mathrm{a} * \mathrm{~b}$ color space as the pre processing step; various color, shape and texture moments for feature extraction and Probabilistic Neural Network for classification. Finally in the latest work performed in 2015 shown in [20], color, texture and shape features namely Global Color Histogram, Color Coherence Vector, Local Binary Patterns, Complete Local Binary Patterns and Zernike Moments were individually to test apples as well as different combinations of them were tested on apple images for images. Results concluded that CCV + CLBP + ZM showed the highest accuracy which $95.9 \%$; which is also the highest till date. The above information is presented below in a tabular format in appendix 1.

\section{CONCLUSION}

The present research paper focuses on defects or diseases found in apple fruit. It shows why quality evaluation of fruits needs to be done using computer vision. It also describes basic diseases found in apple fruit and shows the usual steps involved in quality evaluation of any fruit and examples of its techniques. Finally it includes the work done on quality evaluation of apple fruit thereby considering the techniques used for pre processing, feature extraction and classification; which is also shown in the appendix in the tabular format.

In future, the apple disease recognition and classification can be made more accurate by combining one or more techniques for feature extraction and by using an appropriate classifier according to the application. Also, the choice of technique may vary according to the factor to be considered like speed or accuracy, etc.

\section{REFERENCES}

[1] IndiaRankinAgriculturehttp://www.apeda.gov.in/apedaw ebsite/six_head_product/FFV.htm

[2] India'srankinappleproductionhttp://www.whichcountry.c o/top-10-apple-producing-countries-in-the-world.

[3] Shiv Ram Dubey, Anand Jhalal, "Adapted Approach for Fruit Disease Identification using Images" International Journal of Computer Vision and Image Processing (IJCVIP) 2, no. 3, 2014.
[4] Hartman, J. (2010, April). Apple Fruit Diseases Appearing at Harvest. Plant Pathology Fact Sheet, College of Agriculture, University of Kentucky.

[5] Applescabfactsheethttp://nysipm.cornell.edu/factsheets/tr eefruit diseases/as/as.asp.

[6] Marie-France Destain " Defect segmentation of 'golden delicious' apples using colour machine vision' , Computer and Electronics in Agriculture,1998.

[7] V. Leemans , M.-F. Destain, "A real-time grading method of apples based on features extracted from defects, Elsevier , 2004

[8] Devrim Unay, Bernard Gosselin, "Artificial neural network-based segmentation and apple grading by Machine vision “, IEEE ,2005.

[9] Bin Zhu, Lu Jiang, "Gabor feature-based apple quality inspection using kernel principal component analysis" ,Elsevier ,2007.

[10] K. Vijayarekha "Multivariate image analysis for defect identification of apple fruit image”, IEEE ,2008.

[11] Jin-jing Wang, De-an Zhao, Wei Ji," Application of Support Vector Machine to Apple Recognition using in Apple Harvesting Robot", IEEE International Conference on Information and Automation, 2009.

[12] Rade L. Radojević1, Dragan V. Petrović1," Digital parameterization of apple fruit size, shape and surface spottiness ",African Journal of Agricultural Research Vol. 6(13), pp. 3131-3142, 4 July, 2011.

[13] Devrim Unay, Bernard Gosselin, "Automatic grading of Bi-colored apples by multispectral machine vision”,Elsevier ,2011.

[14] Armin Ghabousian, Mousa Shamsi, "Segmentation of Apple Color Images Utilizing Fuzzy Clustering Algorithms",Advances in Digital Multimedia, March,2012.

[15] A. Gopal , R. Subhasree, Venkatesh. K. Srinivasan," Classification of Color Objects like Fruits using Probability Density Function (PDF)”,IEEE ,2012.

[16] Shivleela R Arlimatti ,"Window Based Method for Automatic Classification of Apple Fruit", International Journal of Engineering Research and Applications, Vol. 2, Issue 4, July-August 2012, pp.1010-1013.

[17] Dubey, S. R., \& Jalal, A. S. ," Detection and Classification of Apple Fruit Diseases using Complete Local Binary Patterns". In Proceedings of the 3rd International Conference on Computer and Communication Technology ,2012.

[18] Rushikesh Borse, Monica Jhuria ," Image processing for smart farming: detection of disease and fruit grading ", Proceedings of the 2013 IEEE International Conference on Image Information Processing(ICIIP-2013).

[19] Vani Ashok ,Dr. D.S. Vinod, "Automatic Quality Evaluation of Fruits Using Probabilistic Neural Network Approach”, IEEE ,2014.

[20] Shiv Ram Dubey, Anand Singh Jalal , "Apple disease classification using color, texture and shape features from images, Springer,2015. 
[21] S.Janardhana, Dr.J.Jaya, "Computer Aided Inspection System For Food Products Using Machine Vision - A Review", International Conference on Current Trends in Engineering and Technology, ICCTET,2013.

[22] Dong ping Tian, “A Review on Image Feature Extraction and Representation Techniques", International Journal of Multimedia and Ubiquitous Engineering Vol. 8, No. 4, July, 2013.

[23] Vijay Satti, "An automatic leaf recognition System for plant Identification using machine Vision technology",
International journal of engineering science and technology, vol. 5 no.04, April 2013.

[24] Saswati Naskar, Tanmay Bhattacharya, "A Fruit Recognition Technique using Multiple Features and Artificial Neural Network", International Journal of Computer Applications (0975 - 8887) Volume 116 - No. 20, April 2015

[25] Ch.Srinivasa Rao, S.Srinivas Kumar," Content Based Image Retrieval using exact Legendre moments and support vector machine" ,International Journal of Multimedia and its applications", May,2010.

\section{APPENDIX}

\begin{tabular}{|c|c|c|c|c|c|c|}
\hline $\begin{array}{l}\text { Publication and } \\
\text { Year }\end{array}$ & $\begin{array}{l}\text { Input } \\
\text { images }\end{array}$ & $\begin{array}{l}\text { No of } \\
\text { images }\end{array}$ & $\begin{array}{l}\text { Pre processing } \\
\text { technique }\end{array}$ & Feature extraction & $\begin{array}{l}\text { Classifier used (if } \\
\text { any) }\end{array}$ & Results \\
\hline $\begin{array}{l}\text { Computer and } \\
\text { Electronics in } \\
\text { Agriculture, } 1998\end{array}$ & $\begin{array}{l}\text { Golden } \\
\text { Delicious } \\
\text { Apples }\end{array}$ & 80 & $\begin{array}{l}\text { Threshold } \\
\text { segmentation. }\end{array}$ & $\begin{array}{l}\text { Global approach: } \\
\text { Median } \\
\text { Interquartile Range } \\
\text { Local approach: } \\
\text { Mean }\end{array}$ & & $\begin{array}{l}\text { Local approach } \\
\text { gave better results. }\end{array}$ \\
\hline $\begin{array}{l}\text { Elsevier, } \\
2004\end{array}$ & $\begin{array}{l}\text { Jonagold } \\
\text { Apples }\end{array}$ & 100 & $\begin{array}{l}\text { Threshold } \\
\text { segmentation }\end{array}$ & $\begin{array}{l}\text { Color: Mean } \\
\text { Color Index } \\
\text { Shape: Area } \\
\text { Major Inertia moment } \\
\text { Texture: Standard deviation }\end{array}$ & $\begin{array}{l}\text { Quadratic } \\
\text { Discriminant } \\
\text { Analysis }\end{array}$ & $73 \%$ accuracy \\
\hline $\begin{array}{l}\text { IEEE, } \\
2005\end{array}$ & $\begin{array}{l}\text { Jonagold } \\
\text { apples }\end{array}$ & 500 & $\begin{array}{l}\text { Artificial Neural } \\
\text { Network based } \\
\text { segmentation }\end{array}$ & $\begin{array}{l}\text { Average } \\
\text { Standard Deviation } \\
\text { Defected Ratio }\end{array}$ & $\begin{array}{l}\text { 1. LDC } \\
\text { 2. k-NN } \\
\text { 3. fuzzy k-NN } \\
\text { 4. SVM } \\
\text { 5. Adaboost }\end{array}$ & $\begin{array}{l}\text { Adaboost and SVM } \\
\text { had highest } \\
\text { accuracy of } 90.3 \%\end{array}$ \\
\hline $\begin{array}{l}\text { Elsevier, } \\
2007\end{array}$ & $\begin{array}{l}\text { Golden } \\
\text { delicious } \\
\text { apples }\end{array}$ & 166 & $\begin{array}{l}\text { Gabor wavelet } \\
\text { decomposition }\end{array}$ & Gabor feature vectors & $\begin{array}{l}\text { 1.Gabor-kernel PCA } \\
\text { 2. PCA } \\
\text { 3. SVM } \\
\text { 4. Gabor PCA } \\
\text { 5. kernel PCA }\end{array}$ & $\begin{array}{l}\text { Gabor-kernel PCA } \\
\text { has the highest } \\
\text { accuracy of } 90.5 \% \text {. }\end{array}$ \\
\hline $\begin{array}{l}\text { IEEE, } \\
2008\end{array}$ & $\begin{array}{l}\text { Normal } \\
\text { apples }\end{array}$ & 46 & $\begin{array}{l}\text { Reorganization of } \\
\text { multivariate } \\
\text { image }\end{array}$ & $\begin{array}{l}\text { Score plots, } \\
\text { Scatter plots }\end{array}$ & PCA & \\
\hline $\begin{array}{l}\text { IEEE, } \\
2009\end{array}$ & Fuji apples & & $\begin{array}{l}\text { Vector Median } \\
\text { Filter }\end{array}$ & $\begin{array}{l}\text { 1.Segmentation based Region } \\
\text { growing method } \\
\text { 2. Color : Euclidian distance } \\
\text { 3. Shape : Round variance } \\
\text { Eclipse variance } \\
\text { Tightness } \\
\text { Ratio of perimeter } \\
\text { and square area }\end{array}$ & SVM & $\begin{array}{l}\text { Classification rate } \\
\text { of apple based on } \\
\text { color and shape } \\
\text { was better than that } \\
\text { of apple based on } \\
\text { color or shape. }\end{array}$ \\
\hline $\begin{array}{l}\text { African journal } \\
\text { of agricultural } \\
\text { research } \\
, 2011\end{array}$ & $\begin{array}{l}\text { Golden } \\
\text { delicious } \\
\text { apples }\end{array}$ & & $\begin{array}{l}\text { Conversion of } \\
\text { color image into } \\
256 \text { gray-level } \\
\text { scale image }\end{array}$ & $\begin{array}{l}\text { Digital parameterization for } \\
\text { measuring shape and size }\end{array}$ & & $\begin{array}{l}\text { Quantitative } \\
\text { parameterization } \\
\text { can be effectively } \\
\text { done using } \\
\text { proposed method. }\end{array}$ \\
\hline $\begin{array}{l}\text { Elsevier, } \\
2011\end{array}$ & $\begin{array}{l}\text { Jonagold } \\
\text { apples }\end{array}$ & & $\begin{array}{l}\text { Segmentation } \\
\text { based on MLP } \\
\text { method }\end{array}$ & $\begin{array}{c}\text { Statistical: Arithmetic mean } \\
\text { Standard deviation } \\
\text { Median } \\
\text { Minimum } \\
\text { Maximum } \\
\text { Textural : Contrast } \\
\text { Angular second moment } \\
\text { Sum-of-squares Variance } \\
\text { Invariant moments of Hu } \\
\text { Geometric : Defect ratio } \\
\text { Perimeter } \\
\text { Circularity }\end{array}$ & $\begin{array}{l}\text { Statistical: } \\
\text { LDC } \\
\text { k-NN } \\
\text { fuzzy k-NN } \\
\text { SVM } \\
\text { Syntactical: } \\
\text { Decision tree } \\
\text { C4.5 }\end{array}$ & $\begin{array}{l}\text { Statistical } \\
\text { classifiers gave } \\
\text { better performance }\end{array}$ \\
\hline
\end{tabular}




\begin{tabular}{|c|c|c|c|c|c|c|}
\hline $\begin{array}{l}\text { Advances in } \\
\text { Digital } \\
\text { Multimedia,2012 } \\
\end{array}$ & Normal & & $\begin{array}{l}\text { Active contour } \\
\text { model }\end{array}$ & Fuzzy C- Means algorithm & & \\
\hline $\begin{array}{l}\text { IEEE, } \\
2012\end{array}$ & $\begin{array}{l}\text { Red } \\
\text { delicious, } \\
\text { Fuji, } \\
\text { Royal gala }\end{array}$ & 187 & $\begin{array}{l}\text { Conversion from } \\
\text { RGB to HSI color } \\
\text { model }\end{array}$ & $\begin{array}{l}\text { Mean } \\
\text { Median } \\
\text { PDF } \\
\text { Histogram intersection }\end{array}$ & & $\begin{array}{l}\text { PDF and histogram } \\
\text { intersection } \\
\text { can significantly } \\
\text { reduce overlap of } \\
\text { grades. }\end{array}$ \\
\hline $\begin{array}{l}\text { International } \\
\text { Journal of } \\
\text { Engineering } \\
\text { Research and } \\
\text { Applications, } \\
2012\end{array}$ & Normal & 210 & $\begin{array}{l}\text { 1.Conversion into } \\
\text { HSV color space } \\
\text { and thresholding } \\
\text { 2. transforming } \\
\text { image into several } \\
\text { windows or } \\
\text { planes }\end{array}$ & $\begin{array}{l}\text { Mean } \\
\text { Standard Deviation }\end{array}$ & $\begin{array}{l}\text { Nearest neighbour } \\
\text { classifier }\end{array}$ & \\
\hline $\begin{array}{l}\text { IEEE, } \\
2012\end{array}$ & Normal & 431 & $\begin{array}{l}\text { 1.Conversion into } \\
\mathrm{L}^{*} \mathrm{a}^{*} \mathrm{~b}^{*} \text { color } \\
\text { space } \\
\text { 2. K-means } \\
\text { Clustering }\end{array}$ & $\begin{array}{l}\mathrm{GCH} \\
\mathrm{CCV} \\
\mathrm{LBP} \\
\mathrm{CLBP}\end{array}$ & Multiclass SVM & $\begin{array}{l}\text { CLBP feature gave } \\
\text { highest accuracy of } \\
90 \% \text {. }\end{array}$ \\
\hline $\begin{array}{l}\text { IEEE, } \\
2013\end{array}$ & Normal & & $\begin{array}{l}\text { Conversion from } \\
\text { RGB to HSI color } \\
\text { model }\end{array}$ & $\begin{array}{l}\text { Color: Histogram difference } \\
\text { Morphology: Erosion } \\
\text { Texture: Homogeneity }\end{array}$ & $\begin{array}{l}\text { Back propagation } \\
\text { Neural Network }\end{array}$ & $\begin{array}{l}\text { Color and } \\
\text { morphology gave } \\
\text { better results as } \\
\text { compared to } \\
\text { texture. }\end{array}$ \\
\hline $\begin{array}{l}\text { IEEE, } \\
2014\end{array}$ & Normal & 65 & $\begin{array}{l}\text { Global threshold } \\
\text { segmentation in } \\
\text { L*a*b* color } \\
\text { space }\end{array}$ & $\begin{array}{l}\text { Mean Boundary Gradient } \\
\text { Mean intensity } \\
\text { Fourier descriptors } \\
\text { Filler blank } \\
\text { Invariant moments }\end{array}$ & $\begin{array}{l}\text { Probabilistic Neural } \\
\text { Network }\end{array}$ & $\begin{array}{l}\text { Accuracy was } \\
\text { around } 88.33 \% \text {. }\end{array}$ \\
\hline $\begin{array}{l}\text { Springer, } \\
2015\end{array}$ & Normal & 320 & $\begin{array}{l}\text { K-means } \\
\text { Clustering }\end{array}$ & $\begin{array}{l}\text { GCH } \\
\text { CCV } \\
\text { LBP } \\
\text { CLBP } \\
\text { Zernike moments }\end{array}$ & Multiclass SVM & $\begin{array}{l}\text { Combination of } \\
\text { CCV+CLBP+ZM } \\
\text { showed the highest } \\
\text { accuracy of } \\
95.94 \% \text {. }\end{array}$ \\
\hline
\end{tabular}

\section{LIST OF ABBREIVATIONS}

PCA: Principal Component Analysis

k-NN: k- Nearest Neighbour

SVM: Support Vector Machine

LDC: Linear Discriminant Classifier

MLP: Multi layer Perceptron

PDF: Probability Density Function

GCH: Global Color Histogram

CCV: Color Coherence Vector

LBP: Local Binary Pattern

CLBP: Complete Local Binary Pattern 